\title{
Genetic Diversity of Provitamin A Cassava in Uganda
}

\author{
Williams Esuma \\ National Crops Resources Research Institute, PO Box 7084, Kampala, Uganda \\ Patrick Rubaihayo \\ Department of Agricultural Production, Makerere University, PO Box 7062, Kampala, Uganda \\ Anthony Pariyo \& Robert Kawuki \\ National Crops Resources Research Institute, PO Box 7084, Kampala, Uganda \\ Bramwel Wanjala \\ Biosciences eastern and central Africa-International Livestock Research Institute (BecA-ILRI) Hub \\ PO Box 30709, Nairobi, Kenya \\ Inosters Nzuki \\ Biosciences eastern and central Africa-International Livestock Research Institute (BecA-ILRI) Hub \\ PO Box 30709, Nairobi, Kenya \\ Jagger JW Harvey \\ Biosciences eastern and central Africa-International Livestock Research Institute (BecA-ILRI) Hub \\ PO Box 30709, Nairobi, Kenya \\ Yona Baguma (Corresponding author) \\ National Crops Resources Research Institute, PO Box 7084, Kampala, Uganda \\ Tel: 256-772-930-185Ｅ-mail: bgmyn@yahoo.co.uk
}

$\begin{array}{lc}\text { Received: December 4, } 2011 \quad \text { Accepted: January 26, } 2012 \quad \text { Published: March 1, } 2012 \\ \text { doi:10.5539/jps.v1n1p60 } & \text { URL: http://dx.doi.org/10.5539/jps.v1n1p60 }\end{array}$

The research was financed by Generation Challenge Program through the Plant Breeders' Community of Practice (CoP) project

\begin{abstract}
Global efforts are being made towards developing provitamin A cassava (Manihot esculenta Cranz) varieties for sustainably addressing vitamin A malnutrition commonly noted in communities where cassava is a major staple. To elucidate the diversity in Uganda's core collection of yellow root cassava germplasm, genetic variability was assessed for 64 yellow and white root cassava accessions including Ugandan landraces, and accessions introduced from the International Center for Tropical Agriculture (CIAT) and the International Institute of Tropical Agriculture (IITA). Phenotypic characterization was based on 12 morphological descriptors, total carotenoid content (TCC) and dry matter content (DMC). Variation of twenty six simple sequence repeat (SSR) markers was assessed and compared with morphological data. Total carotenoid content varied from 1.2 to 14.2 $\mu \mathrm{g} / 100 \mathrm{~g}$ and correlated negatively $\left(R^{2}=-0.46\right)$ with dry matter content which ranged from 27.2 to $39.8 \%$. Genetic diversity was high in all accession groups with an average heterozygosity of $0.5583 \pm 0.0182$. Phenetic
\end{abstract}


analyses using Unweighted Pair Group Method with Arithmetic Mean (UPGMA) and Principle Coordinate Analysis (PCoA) clustered the CIAT accessions into a distinct group, discriminating them from the landraces and IITA accessions. Based on the clustering pattern, it suffices to suggest limited gene flow between CIAT accessions and the landraces/IITA accessions which is an opportunity for broadening the genetic base through hybridization by exploiting the heterotic pool in the germplasm.

Keywords: Provitamin A cassava, Total carotenoid content, Genetic diversity, SSR markers, Cassava genetic improvement

\section{Introduction}

The low nutritional composition of cassava (Manihot esculenta Cranz) is a major factor which underrates the crop as a complete food crop. Notably, vitamin A deficiency (VAD) that ranges from night blindness to Xerophthalmia and Keratomalacia causing total blindness has been noted as a major health hazard in communities whose nutritional security heavily relies on cassava (Gichuki et al., 2010; Rice et al., 2004). It is estimated that globally, over 250 million children are at risk of VAD, $21 \%$ being attributable to heavy reliance on cassava (WHO, 2009). Consequently, cassava is often excluded from the concept of a food-secure world, where all people at all times should have physical, social and economic access to adequate, nutritious, culturally acceptable and safe supply of food to meet their dietary needs and preferences for an actively healthy life (FAO, 2001).

However, existence of yellow root cassava (Sanchez et al., 2006; Nassar, 2007) offers a different perception on nutritional benefits associated with the crop. Enhanced content of $\beta$-carotene (provitamin A) in yellow root cassava (Chavez et al., 2007; Sanchez et al., 2006) provides sufficient opportunity to sustainably address vitamin A malnutrition through deployment of provitamin A cassava varieties where the crop is a major staple (Makokha and Tunze, 2005; Nassar and Ortiz, 2010). It suffices to note that global efforts towards breeding cassava for high $\beta$-carotene content are only recent with low progress registered towards development and deployment of carotene rich varieties to farmers (Hershey, 2011; Ross Welch and Robin Graham, 2004), attributable to the negative association between $\beta$-carotene and dry matter (Vimala et al., 2008; Akinwale et al., 2010). Subsequently, the need for sufficient knowledge on genetic diversity in cassava germplasm collections for use by breeding programmes is a priority for effective utilization of the genetic resources in improvement of the crop (Nassar \& Ortiz, 2007; Nassar \& Ortiz, 2010).

In light of this development, the National Cassava Progamme in Uganda introduced yellow root cassava accessions from CIAT and IITA, under the plant import permit number 000438, for adaptation and evaluation under local field conditions. However, these were the pioneer efforts made in Uganda towards nutrient enhancement in cassava. Therefore, in order to effectively select parental lines to breed for higher $\beta$-carotene content in cassava, it was invaluable to ascertain the genetic diversity of the germplasm. Here, we report the phenotypic and molecular diversity of yellow root cassava germplasm assembled in Uganda.

\section{Materials and Methods}

\subsection{Plant material}

Sixty four cassava accessions maintained at the National Crops Resources Research Institute (NaCRRI) were assayed for phenotypic variability and SSR allele diversity. Fifty five of the accessions were yellow root genotypes: 23 from CIAT, 23 from IITA and nine landraces from Uganda. Nine white root cassava varieties commonly grown by Ugandan and Tanzanian farmers were included for comparison with the yellow root accessions. The names of the accessions are presented in Figure 1.

\subsection{Phenotypic characterization}

The 64 cassava accessions above were assessed for variability in morphological and root quality traits. The root quality traits evaluated were total carotenoid content (TCC) and dry matter content (DMC). To estimate provitamin A content, TCC was measured. This was extracted using acetone and petroleum ether as described by Rodriquez-Amaya and Kimura (2004). Absorbance of the extract was measured at $450 \mathrm{~nm}$ using UV/visible spectrophotometry (Specord 210, Analytikjena model Torre Boldone BG, Italy). TCC was quantified using the formula:

$$
\mathrm{TCC}(\mu \mathrm{g} / \mathrm{g})=\frac{A x V(m L) \times 10^{4}}{2592 \times W}
$$

where: $\mathrm{A}=$ absorbance, $\mathrm{V}=$ total extract volume, $\mathrm{W}=$ sample weight, $2592=\beta$-carotene absorption coefficient in petroleum ether. The yellow pigmentation in cassava roots is predominantly due to $\beta$-carotene (provitamin A). 
Thus the levels of TCC based on spectrophotometric screening give good estimates of $\beta$-carotene in cassava. The white root cassava varieties were not analyzed for TCC because the procedure employed here was only effective enough to measure absorbance of coloured extracts.

To estimate DMC, a 20 - $30 \mathrm{~g}$ fresh root sub-sample obtained from the one used to estimate TCC was dried in oven at $60{ }^{\circ} \mathrm{C}$ for $24 \mathrm{~h}$, and weight before and after drying compared. The morphological descriptors including colour of apical leaf, pubescence, petiole colour, leaf colour, shape of central leaf, number of leaf lobes, lob margins, colour of stem cortex, colour of stem exterior, growth habit, branching habit and shape of plant were evaluated for variability using the standard procedure as described by Fukuda et al. (2010) (Table 1).

\subsection{SSR genotyping}

Genomic DNA was extracted using Dellaporta method (Dellaporta et al., 1983). The DNA was checked for quantity and quality using microvolumetric Nanodrop ND-1000 and diluted to $25 \mathrm{ng} / 100 \mu \mathrm{l}$. The 64 cassava genotypes were assayed with 26 polymorphic SSR markers (Table 2). These markers were selected from 13 of the 18 linkage groups on cassava genome map on the basis of single locus amplification, high degree of polymorphism and reproducibility. Amplification with the SSR primers was performed in $10 \mu 1$ reactions containing $25 \mathrm{ng}$ of DNA template, 1 mole of each primer, $1 \mathrm{X}$ Taq polymerase buffer, $2 \mathrm{mM} \mathrm{MgCl}, 0.2 \mathrm{mM}$ deoxynucleotide phosphates (dNTPs) and $0.37 \mathrm{U}$ Taq polymerase. The PCR profile was $95{ }^{\circ} \mathrm{C}$ for 2 min, followed by 30 cycles of $95{ }^{\circ} \mathrm{C}$ for $30 \mathrm{sec}$, annealing at $55-57^{\circ} \mathrm{C}$ for $1 \mathrm{~min}$, extension at $72{ }^{\circ} \mathrm{C}$ for $1 \mathrm{~min}$ and a final extension at $72{ }^{\circ} \mathrm{C}$ for $30 \mathrm{~min}$. Because amplicons were of different sizes and the forward primers were fluorescently labeled (MWG-Biotech), co-loading of amplicons from the same individual, but at different loci, was therefore possible. Seven co-loading sets were optimized and used for the entire analysis. For each co-loading set, $1-2 \mu 1$ of the different amplicons were mixed and vortexed. Aliquots of $1 \mu \mathrm{l}$ of the mixture were added to $9 \mu \mathrm{l}$ of a master mix containing HiDi formamide and GeneScan 500-LIZ size standard (1 ml of HiDi + $12 \mu \mathrm{l}$ of 500-LIZ). The amplicons were denatured at $95^{\circ} \mathrm{C}$ for $3 \mathrm{~min}$ and subjected to capillary electrophoresis using ABI 3730 DNA sequencer (Applied Biosystems), and allele calls made using GENEMAPPER software version 3.7 (Applied Biosystems).

\subsection{Data analysis}

Descriptive statistics on TCC and DMC were obtained using the Genstat Computer Package. Dissimilarity matrix generated from single morphological data was used for phenetic analysis using DARwin5 software version 5.0.158 (Perrier and Jacquemoud-Collet, 2006). Diallelic data generated from the 26 SSR markers were used to estimate the genetic diversity within and among accessions using PowerMarker software package (version 3.25) described by Liu and Muse (2005), with the following statistics: percentage of polymorphic loci, mean number of alleles per polymorphic locus, average observed heterozygosity $\left(\mathrm{H}_{\mathrm{o}}\right)$, average gene diversity $\left(\mathrm{H}_{\mathrm{e}}\right)$ (Nei, 1978). Dissimilarity matrix generated diallelic SSR data was subjected to principal coordinate analysis (PCoA) using GenAlEx software version 6 (Peakall ans Smouse, 2006).

\section{Results}

\subsection{Variation in total carotenoid content, dry matter content and morphological traits}

TCC varied from 1.2 (in Ugandan landraces) to $14.2 \mu \mathrm{g} / 100 \mathrm{~g}$ (in IITA accessions) (Table 3). IITA accessions had higher mean TCC $(5.5 \pm 2.01 \mu \mathrm{g} / 100 \mathrm{~g})$ and the landraces had the least mean TCC $(4.3 \pm 1.32 \mu \mathrm{g} / 100 \mathrm{~g})$ with skewness of 1.29 and -0.45 respectively. The differences between the TCC means were not significant (LSD, $P<$ 0.05). DMC varied from $27.2 \%$ (in CIAT accessions) to $39.8 \%$ (in local white root varieties) (Table 3 ). The mean DMC of local white root varieties was significantly different (LSD $P<0.05$ ) from means of other accessions, and the same was true with the mean DMC of the yellow root landraces compared to other yellow root accessions.

A phenogram constructed by the Unweighted Pair-Group with Arithmetic Mean (UPGMA) method revealed three clusters within the genotypes evaluated (Figure 1). Clusters II and III were constituted, without clear discrimination, by accessions from IITA, Ugandan landraces and white root varieties, but cluster I was almost entirely constituted by CIAT accessions. The most discriminating morphological traits were shape of the central leaf in which frequency of CIAT genotypes with lanceolate leaves was 0.85 and colour of apical leaf where frequency of CIAT genotypes with purplish green apical colour was 0.73 , however the correlation between the morphological characters and TCC or DMC was not significant.

\subsection{SSR diversity}

The number of alleles per locus averaged at $4.2 \pm 0.16$, with yellow root accessions from IITA having the highest number at an average of 4.7 alleles per locus (Table 4). $\mathrm{H}_{\mathrm{o}}$ was high in all accession groups and ranged 
from 0.47 to 0.66 at an average of $0.57 \pm 0.024$. The expected heterozygosity ranged from 0.51 in white root accessions to 0.60 in CIAT accessions. Total heterozygosity $\left(\mathrm{H}_{\mathrm{T}}\right)$ over all loci was high in all accessions $(0.59 \pm$ $0.11)$, but only $4.7 \%\left(\mathrm{G}_{\mathrm{ST}}=0.047 \pm 0.0551\right)$ was due to differentiation among accession groups i.e., between CIAT, IITA, Uganda and white root accessions. Most of the diversity was found within accession groups $\left(\mathrm{H}_{\mathrm{S}}=\right.$ $0.56 \pm 0.099$, Table 4). Indeed, analysis of molecular variance (AMOVA) showed that most of the variation was distributed within populations $(80 \%)$ and the rest distributed among populations (Table 5), corroborating the genetic diversity results above.

An examination of genetic relationship between accessions using both UPGMA (Figure 2) and PCoA (Figure 3) methods confirmed the three clusters. The three main eigenvalues of the PCoA on the similarity matrix explained $33 \%, 19 \%$ and $15 \%$ of the total variation, respectively. In both cases, the CIAT accessions clustered into distinct group while mixtures of IITA and Ugandan accessions constituted the other two clusters.

\section{Discussion}

The wide range of TCC and DMC, and distribution of morphological variability in the cassava accessions analyzed here provide a broader scope for the crop's improvement through hybridization and selection. Although the inverse relationship between TCC and DMC reported in this study and elsewhere by Vimala et al. (2008) and Akinwale et al. (2010) may be undesirable where high DMC is preferred, independent inheritance of $\beta$-carotene and DMC (Akinwale et al., 2010; Nasser and Rodomiro, 2010) makes selection from populations segregating for the traits effective in developing pro-vitamin A cassava varieties. The higher DMC observed in local white root varieties and the landraces is most likely resulting from the effect of selection by farmers. During cassava variety development, high DMC is a priority trait at yield evaluation stage, and farmers tend to maintain landraces with good root qualities among which is DMC (Nassar et al., 2009; Hershey, 2011).

The wide genetic variability of yellow root cassava, confirmed by comparison with popular white root accessions, further confirms the value of this germplasm collection for breeding efforts that include provitamin A as one of several important traits. Values of $\mathrm{H}_{\mathrm{o}}$ and $\mathrm{H}_{\mathrm{e}}$ showed moderate amounts of heterozygotes in the populations studied. The broad genetic base of cassava in South America (Olsen and Schaal, 2001) can account for the relatively high heterozygosity observed in CIAT accessions. However, recombination events during hybridization could explain the comparably high heterozygosity in both CIAT and IITA accessions. Since their establishment in the 1970s, CIAT and IITA have been greatly involved in production of improved cassava varieties in Colombia and Nigeria, respectively. This has been achieved through controlled hybridization, sometimes using diverse exotic parents, thus providing high levels of genetic variability (Glazmann et al., 2010). The mean number of alleles (4.25) detected per locus is similar to those obtained in previous cassava diversity studies (Fregene et al. 2003; Raghu et al., 2007; Siqueira et al., 2009), attesting to the heterozygous nature of cassava as an out-crossing crop. The genetic differences observed between the white root and the yellow root accessions in this study cannot be associated with provitamin A because the SSR markers used were neutral.

The relatively high heterozygosity found in the landraces studied can be attributed to farmers' role in selection and maintenance of desirable genotypes. It is also possible that genotypes classified as landraces could be hybrids derived through local $\mathrm{x}$ elite hybridisations. Kizito (2006) noted that during periods of scarcity of planting materials, subsistence farmers generated their own materials from cuttings of cassava plants in forests or fields in a fallow and from volunteer plants derived from sexually reproduced seedlings. This practice favors heterozygosity in cassava because as farmers select for vigor among spontaneous seedlings, they indirectly select for heterozygous genotypes (Jarvis \& Hodgkin, 1999). The variability in the landraces may be associated with favorable genes which are often the most appropriate background into which a breeder can introduce new traits (Nasser 2007; Siqueira et al., 2009). As such, the landraces may form the nucleus of germplasm assemblage for $\beta$-carotene because farmers often have selected these clones for many years for adaptation, cultural practices and quality traits required by local markets (Nasser, 2007).

\section{Conclusion}

Collectively, the core Ugandan cassava germplasm collection now including Ugandan landraces, as well as accessions introduced from CIAT and IITA represents a valuable resource for inclusion of high provitamin A as a trait in the national breeding program. This study now allows informed breeding strategies to be devised and executed. The high level of differentiation between CIAT and IITA yellow root cassava accessions represents a heterotic pool, presenting an opportunity for systematic exploitation of hybrid vigor to create broader genetic base for developing pro-vitamin A varieties. Additionally, the diversity in Ugandan yellow root cassava landraces presents an invaluable germplasm resource for cassava genetic improvement targeted to the region. The results provide a starting point for establishing a functional conservation strategy and for inclusion of 
provitamin A as a trait in Ugandan national cassava breeding, targeting utilization of the yellow root accessions for cassava genetic improvement.

\section{Acknowledgements}

The financial support provided by Generation Challenge Program (GCP) through Cassava Breeders' Community of Practice (CoP) supported this work. Genotyping was conducted at the BecA-ILRI Hub, making use of its infrastructure, scientific competencies and research-related services (http://hub.africabiosciences.org).

\section{References}

Akinwale, M. G., Aladesanwa, R. D., Akinyele, B. O., Dixon, A. G. O., \& Odiyi, A. C. (2010). Inheritance of $\beta$-carotene in cassava (Manihot esculenta crantza). International Journal of Genetics and Molecular Biology, 2(10), 198-201.

Chavez, A. L., Sanchez, T., Ceballos. H., Rodriguez-Amaya, D. B., Nestel, P., Tohme, J., \& Ishitani, M. (2007). Retention of carotenoids in cassava roots submitted to different processing methods. Journal of the Science of Food and Agriculture, 86, 634-639.

Dellaporta, S., Wood, J., \& Hicks, J. (1983). A plant DNA minipreparation: Version II. Plant Molecular Biology Reporter, 1(14), 19-21.

FAO. (2001). Food insecurity: when people live with hunger and fear starvation. The State of Food Insecurity in the World 2001. FAO, Rome.

Fregene, M., Suarez, M., Mkumbira, J., Kulembeka, H., Ndedya, E., Kulaya, A., Mitchel, S., Gullberg, U., Rosling, H, Dixon, A. G. O., Dean, R., \& Kresovich S. (2003). Simple sequence repeat marker diversity in cassava landraces: genetic diversity and differentiation in an asexually propagated crop. Theoretical and Applied Genetics, 107, 1083-1093.

Fukuda, W. M. G., Guevara, C. L., Kawuki, R., \& Ferguson, M. E. (2010). Selected morphological and agronomic descriptors for the characterization of cassava. International Institute of Tropical Agriculture (IITA), Ibandan, Nigeria. $19 \mathrm{pp}$.

Gichuki, S., Ada, M., \& Mark, M. (2010). Consuming cassava as a staple food places children 2-5 years old at risk for inadequate protein intake, an observational study in Kenya and Nigeria. Nutrition Journal, 9, 9-15.

Glazmann, J. C., Kilian, B., Upadhyaya, H. D., \& Varshney, R. K. (2010). Assessing genetic diversity for crop improvement. Current Opinion in Plant Biology, 13, 1-7.

Hershey, C. (2011). Cassava breeding: Theory and practice. A publication by Food and Agriculture Organisation (FAO), In press.

Jarvis, D. I., \& Hodgkin, T. (1999). Wild relatives and crop cultivars: detecting natural introgression and farmer selection of new genetic combinations in agroecosystems. Molecular ecology, 8, S159-S173.

Kizito, E. (2006). Genetic and root growth studies in cassava (Manihot esculenta Crantz): implications for breeding. [Online] Available: http:/dissepsilon.slu.se:8080/archieve/01/E.B._Kizito's_thesis.pdf (June 2009)

Liu, K. J., \& Muse, S. V. (2005). Power Marker: an integrated analysis environment for genetic marker analysis. Bioinformatics, 21, 2128-2129.

Makokha, A. O., \& Tunje, T. K. (2005). Potential for alleviating vitamin A deficiency in East Africa through cassava and sweet potato tubers. African Crop Science Conference Proceedings, 7, 643-646

Morante, N., Sanchez, T., Ceballos, H., Calle, F., Perez, J. C., Egesi, C., Cuambe, C. E., Escobar, A. F., Ortiz, D., Chavez, A. L., \& Fregene, M. (2010). Tolerance to post harvest physiological deterioration in cassava roots. Crop Science, 50, 1333-1338.

Nassar, N. (2007). Cassava genetic resources and their utilization for breeding of the crop. Genetics and Molecular Research, 6(4), 1151-1168.

Nasser, N., \& Ortiz, R. (2010). Breeding cassava to feed the poor. Scientific American, 302(5), 78-82.

Nei, M. (1978). Estimation of average heterozygosity and genetic distance from a small number of individuals. Genetics, 89, 583-590.

Nassar Nagib., \& Ortiz, Rodomiro. (2007). Cassava improvement: challenges and impacts. Journal of Agricultural Science, 145, 163-171. 
Nassar Nagib, Osmindo Junior, Marcelo Sousa, \& Rodomiro Ortiz. (2009). Improving Carotenoids and Amino-Acids in Cassava. Recent Patents on Food, Nutrition \& Agriculture, 1, 32-38.

Olsen, K., \& Schaal, B. (2001). Microsatellite variation in cassava (Manihot esculenta Cranz) and its wild relatives: further evidence for a southern Amazonian origin of domestication. American Journal of Botany, 88, 131-142.

Peakall, R., \& Smouse, P. E. (2006). GENEALEX 6: genetic analysis in Excel. Population genetic software for teaching and research. Molecular Ecology Notes, 6, 288-295.

Perrier X \& Jacquemoud-Collet JP. (2006). DARwin software. [Online] Available: http://darwin.cirad.fr/darwin (November 2010)

Raghu, D., Senthil, N., Saraswathi, T., Raveendran, M., Gnanam, R., Venkatachalam, R., Shanmugasundaram, P., \& Mohan, C. (2007). Morphological and simple sequence repeats (SSR) based fingerprinting of South Indian cassava germplasm. International Journal of Integrative Biology, 1(2), 142-148.

Rodriguez-Amaya B. Delia, \& Mieko Kimura. (2004). HarvestPlus Handbook for Carotenoid Analysis. Washington, DC and Cali: International Food Policy Research Institute (IFPRI) and International Center for Tropical Agriculture (CIAT). Online: Available at: http://www.ifpri.org/sites/default/files/publications/hptech02.pdf

Rice, A. L., West, K. P., \& Black, R. E. (2004). Vitamin A deficiency, in Comparative Quantification of Health Risks: Global and regional burden of disease attributable to selected major risk factors, ed. by Ezzati M, Lopez A.D, Rodgers A and Murray C.J.L. World Health Organization, Geneva, 211-256.

Ross Welch, \& Robin Graham. (2004). Breeding for micronutrients in staple food crops from a human nutrition perspective. Journal of Experimental Botany, 55(396), 353-364.

Sanchez, T., Chavez, A. L., Ceballos, H., Rodriquez-Amaya, D. B., Nestel, P., \& Ishitani, M. (2006). Reduction or delay of post-harvest physiological deterioration in cassava roots with higher carotenoid content. Journal of the Science of Food and Agriculture, 86, 634-639.

Siqueira, M. V., Jurema, R., Queiroz, S., Eduardo, A, Aline, B., Kayo, J. C, Jose, G., \& Elizabeth, A. (2009). Genetic characterization of cassava (Manihot esculenta) landraces in Brazil assessed with simple sequence repeats. Genetics and Molecular Biology, 32(1), 104-110.

Vimala, B., Nambisan, B., Theshara, R., \& Munnikrishnam. (2008). Variability of Carotenoids in yellow-flesh cassava (Manihot esculatar Crantz). Geneconserve. Pro. br. pp 1.

WHO. (2009). Global prevalence of vitamin A deficiency in populations at risk 1995-2005: Geneva, Switzerland. [Online] Available: http://whqlibdoc.who.int/publications/2009/pdf (May 2010) 
Table 1. Traits and assessment procedure for morphological characterization of landraces

\begin{tabular}{|c|c|c|c|}
\hline Trait evaluated & $\begin{array}{l}\text { Age }^{*} \\
\text { (month) }\end{array}$ & Scale for evaluation & Remark \\
\hline $\begin{array}{l}\text { Colour of apical } \\
\text { leaf }\end{array}$ & 3 & $\begin{array}{l}\text { 3-Light green; 5-Dark green; 7-Purplish green; } \\
\text { 9-Purple }\end{array}$ & Top three leaves considered \\
\hline Pubescence & 3 & 0-Absent; 1-Present & Top three leaves considered \\
\hline Petiole colour & 6 & $\begin{array}{l}\text { 1-Yellowish green; 2-Green; 3-Reddish green; } \\
\text { 5-Greenish red; 7-Red; 9-Purple }\end{array}$ & $\begin{array}{l}\text { Leaf taken from a mid-height } \\
\text { position }\end{array}$ \\
\hline Leaf colour & 6 & $\begin{array}{l}\text { 3-Light green; 5-Dark green; 7-Purplish green; } \\
\text { 9-Purple }\end{array}$ & $\begin{array}{l}\text { A leaf from middle of the plant } \\
\text { observed }\end{array}$ \\
\hline $\begin{array}{l}\text { Shape of central } \\
\text { leaf }\end{array}$ & 6 & $\begin{array}{l}\text { 1-Ovoid; 2-Elliptic-lanceolate; } \\
\text { 3-Obovate-lanceolate; 4-Oblong-lanceolate; } \\
\text { 5-Lanceolate; 6-Strait or linear; 7-Pandurate; } \\
\text { 8-Linear-piramidal; 9-Linear-pandurate; } \\
\text { 10-Linear-hostatilobalate }\end{array}$ & $\begin{array}{l}\text { Leaf taken from a mid-height } \\
\text { position }\end{array}$ \\
\hline $\begin{array}{c}\text { Number of leaf } \\
\text { lobes }\end{array}$ & 6 & $\begin{array}{l}\text { 3-Three lobes; 5-Five lobes; 7-Seven lobes; } \\
\text { 9-Nine lobes; 11-Eleven lobes }\end{array}$ & $\begin{array}{l}\text { A leaf taken from a mid-height } \\
\text { position }\end{array}$ \\
\hline Lobe margins & 6 & 3-Smooth; 7-Winding & $\begin{array}{l}\text { A leaf from the middle third of the } \\
\text { plant observed }\end{array}$ \\
\hline $\begin{array}{c}\text { Colour of stem } \\
\text { cortex }\end{array}$ & 9 & 1-Orange; 2-Light green; 3-Dark green & $\begin{array}{l}\text { A leaf from the middle third of the } \\
\text { plant observed }\end{array}$ \\
\hline $\begin{array}{l}\text { Colour of stem } \\
\text { exterior }\end{array}$ & 9 & $\begin{array}{l}\text { 3-Orange; 4-Greeny-yellowish; 5-Golden; } \\
\text { 6-Light brown; 7-Silver; 8-Grey; 9-Dark } \\
\text { brown }\end{array}$ & $\begin{array}{l}\text { A leaf from the middle third of the } \\
\text { plant observed }\end{array}$ \\
\hline Growth habit & 9 & 1-Straight; 2-Zigzag & Most occurrence considered \\
\hline Branching habit & 12 & $\begin{array}{l}\text { 1-Erect; 2-Dichotomous; 3-Trichotomous; } \\
\text { 4-Tetrachotomous }\end{array}$ & Observed at first branching \\
\hline Shape of plant & 12 & $\begin{array}{l}\text { 1-Compact; 2-Open; 3-Umbrella; } \\
\text { 4-Cylindrical }\end{array}$ & Most occurrence considered \\
\hline $\begin{array}{c}\text { Extent of root } \\
\text { peduncle }\end{array}$ & 12 & 0-Sessile; 3-Pendunculate; Mixed & Main roots considered \\
\hline $\begin{array}{c}\text { Root } \\
\text { constrictions } \\
\end{array}$ & 12 & 1-Few to none; 2-Some; 3-Many & Measured on mature roots \\
\hline Root shape & 12 & $\begin{array}{c}\text { 1-Conical; 2-Conical-cylindrical; } \\
\text { 3-Cylindrical; 4-Irregular }\end{array}$ & Most occurrence considered \\
\hline $\begin{array}{c}\text { Color of root } \\
\text { cortex }\end{array}$ & 12 & 1-White or cream; 2-Yellow; 3-Pink; 4-Purple & Most occurrence considered \\
\hline
\end{tabular}

${ }^{*}$ The traits were evaluated at different developmental stages of the plants, as described by Fukuda et al. (2010) 
Table 2. Optimized co-loading sets of 26 SSR primers based on amplicon size and dye colour

\begin{tabular}{|c|c|c|c|c|c|c|c|}
\hline SSR locus & Forward primer sequence & Reverse primer sequence & $\mathrm{LG}^{1}$ & $\mathrm{CS}^{2}$ & $\begin{array}{l}\text { Amplicon } \\
\text { size }\end{array}$ & Dye label $^{3}$ & $\begin{array}{l}\text { Annealing } \\
\text { temp }\left({ }^{\circ} \mathrm{C}\right)\end{array}$ \\
\hline SSRY21 & CCTGCCACAATATTGAAATGG & CAACAATTGGACTAAGCAGCA & $\mathrm{B} / \mathrm{D}$ & 1 & $120-230$ & NED & 57 \\
\hline SSRY38 & GGCTGTTCGTGATCCTTATTAAC & GTAGTTGAGAAAACTTTGCATGAG & G & 1 & $80-140$ & 6-FAM & 57 \\
\hline SSRY59 & GCAATGCAGTGAACCATCTTT & CGTTTGTCCTTTCTGATGTTC & M & 1 & $130-180$ & PET & 55 \\
\hline SSRY69 & AACTGTCAAACCATTCTACTTGC & GCCAGCAAGGTTTGCTACAT & $\mathrm{F}$ & 1 & $180-270$ & VIC & 57 \\
\hline NS911 & CACGACGTTGTAAAACGAC & TGTTGTTCAGACGATGTCCAA & nd & 2 & $90-150$ & VIC & 59 \\
\hline SSRY5 & TGATGAAATTCAAAGCACCA & CGCCTACCACTGCCATAAAC & $\mathrm{J}$ & 2 & $70-150$ & 6-FAM & 57 \\
\hline SSRY52 & GCCAGCAAGGTTTGCTACAT & AACTGTCAAACCATTCTACTTGC & $\mathrm{H}$ & 2 & $230-280$ & PET & 57 \\
\hline SSRY161 & AAGGAACACCTCTCCTAGAATCA & CCAGCTGTATGTTGAGTGAGC & nd & 2 & $200-240$ & NED & 55 \\
\hline SSRY9 & ACAATTCATCATGAGTCATCAACT & CCGTTATTGTTCCTGGTCCT & $\mathrm{D}$ & 3 & $245-285$ & VIC & 57 \\
\hline SSRY110 & TTGAGTGGTGAATGCGAAAG & AGTGCCACCTTGAAAGAGCA & $\mathrm{L}$ & 3 & $230-260$ & PET & 57 \\
\hline SSRY151 & CACGACGTTGTAAAACGAC & AGTGGAAATAAGCCATGTGATG & nd & 3 & $160-240$ & 6-FAM & 57 \\
\hline SSRY155 & CACGACGTTGTAAAACGAC & CGTTGATAAAGTGGAAAGAGCA & nd & 3 & $130-180$ & NED & 59 \\
\hline SSRY12 & AACTGTCAAACCATTCTACTTGC & GCCAGCAAGGTTTGCTACAT & $\mathrm{F} / \mathrm{H}$ & 4 & $220-290$ & NED & 57 \\
\hline SSRY100 & ATCCTTGCCTGACATTTTGC & TTCGCAGAGTCCAATTGTTG & $\mathrm{K}$ & 4 & $170-280$ & PET & 57 \\
\hline SSRY102 & TTGGCTGCTTTCACTAATGC & TTGAACACGTTGAACAACCA & M & 4 & $160-200$ & 6-FAM & 57 \\
\hline SSRY147 & CACGACGTTGTAAAACGAC & GTACATCACCACCAACGGGC & nd & 4 & $80-140$ & VIC & 57 \\
\hline SSRY63 & TCAGAATCATCTACCTTGGCA & AAGACAATCATTTTGTGCTCCA & $\mathrm{H}$ & 5 & $240-340$ & PET & 57 \\
\hline SSRY148 & CACGACGTTGTAAAACGAC & GGCTTCATCATGGAAAAACC & nd & 5 & $90-140$ & VIC & 57 \\
\hline SSRY181 & GGTAGATCTGGATCGAGGAGG & CAATCGAAACCGACGATACA & $\mathrm{K}$ & 5 & $130-230$ & 6-FAM & 57 \\
\hline SSRY182 & GGAATTCTTTGCTTATGATGCC & TTCCTTTACAATTCTGGACGC & M & 5 & $190-260$ & NED & 57 \\
\hline SSRY135 & CCAGAAACTGAAATGCATCG & AACATGTGCGACAGTGATTG & G & 6 & $230-265$ & PET & 57 \\
\hline SSRY169 & ACAGCTCTAAAAACTGCAGCC & AACGTAGGCCCTAACTAACCC & $\mathrm{D}$ & 6 & $70-130$ & 6-FAM & 55 \\
\hline SSRY171 & ACTGTGCCAAAATAGCCAAATAGT & TCATGAGTGTGGGATGTTTTTATG & $\mathrm{C}$ & 6 & $240-330$ & NED & 55 \\
\hline SSRY19 & GCCAGCAAGGTTTGCTACAT & TCTCCTGTGAAAAGTGCATGA & K & 7 & $190-250$ & 6-FAM & 57 \\
\hline SSRY51 & AGGTTGGATGCTTGAAGGAA & GGATGCAGGAGTGCTCAACT & I & 7 & $230-330$ & PET & 57 \\
\hline SSRY64 & CGACAAGTCGTATATGTAGTATTCACG & GCAGAGGTGGCTAACGAGAC & $\mathrm{J}$ & 7 & $160-230$ & VIC & 57 \\
\hline
\end{tabular}

${ }^{1}$ Linkage group on cassava genome map, the alphabets represent the chromosomes on which the primers are located; ${ }^{2}$ Co-loading set; ${ }^{3} \mathrm{PET}=$ Red, VIC $=$ Green, NED $=$ Yellow, 6-FAM $=$ Blue; nd $=$ no linkage data

Table 3. Carotenoid and dry matter content of yellow root cassava accessions

\begin{tabular}{cccccccccr}
\hline \multirow{2}{*}{$\begin{array}{c}\text { Accession } \\
\text { source/type }\end{array}$} & No. of & \multicolumn{3}{c}{ TCC $(\mu \mathrm{g} / 100 \mathrm{~g})$} & \multicolumn{3}{c}{ DMC $(\%)$} \\
\cline { 2 - 10 } & genotypes & Min. & Max. & Mean & Min. & Max. & Mean & TCC & DMC \\
\hline CIAT & 23 & 1.3 & 10.2 & $5.2 \pm 2.41$ & 27.2 & 35.6 & $32.8 \pm 0.62$ & -0.61 & 0.11 \\
IITA & 23 & 1.5 & 14.2 & $5.5 \pm 2.01$ & 28.3 & 35.1 & $33.1 \pm 1.55$ & 1.29 & -0.58 \\
UGLR $^{1}$ & 9 & 1.2 & 7.8 & $4.3 \pm 1.32$ & 32.6 & 36.5 & $34.9 \pm 1.27$ & -0.45 & -0.33 \\
LWRV $^{2}$ & 9 & - & - & - & 35.3 & 39.8 & $37.4 \pm 2.11$ & - & 0.09 \\
\hline
\end{tabular}

${ }^{1}$ Ugandan yellow root landraces, ${ }^{2}$ Local white root varieties (TCC was not analysed in the white root accessions because the TCC levels were below the minimum threshold detectable by the spectrophotometry protocol) 
Table 4. Estimates of genetic diversity parameters of yellow root cassava accessions from different groups

\begin{tabular}{ccccccc}
\hline Population & Sample size & Alleles/locus & $\mathrm{H}_{\mathrm{o}}$ & $\mathrm{H}_{\mathrm{e}}$ & $\mathrm{H}_{\mathrm{ec}}{ }^{1}$ & $\mathrm{~F}_{\text {isp }}{ }^{2}$ \\
\hline CIAT & 23 & 4.5 & 0.66 & 0.60 & 0.62 & -0.09 \\
IITA & 23 & 4.7 & 0.59 & 0.59 & 0.61 & 0.06 \\
LWRV & 9 & 3.7 & 0.47 & 0.51 & 0.54 & 0.25 \\
UGLR & 9 & 3.8 & 0.55 & 0.54 & 0.57 & -0.03 \\
Mean & & 4.2 & 0.57 & 0.56 & 0.58 & -0.01 \\
SD & & 0.16 & 0.02 & 0.02 & 0.02 & 0.03 \\
& $\mathrm{H}_{\mathrm{T}}$ & $\mathrm{H}_{\mathrm{S}}{ }^{3}$ & $\mathrm{D}_{\mathrm{ST}}{ }^{2}$ & $\mathrm{G}_{\mathrm{ST}}{ }^{2}$ & & \\
Mean & 0.5922 & 0.56 & 0.03 & 0.047 & & \\
$\mathrm{SD}^{6}$ & 0.1104 & 0.10 & 0.03 & 0.055 & & \\
$95 \% \mathrm{CI}^{7}$ & 0.7103 & 0.66 & 0.02 & 0.031 & & \\
$99 \% \mathrm{CI}^{7}$ & 0.8122 & 0.78 & 0.04 & 0.068 & & \\
\hline
\end{tabular}

${ }^{1}$ Mean expected heterozygosity corrected for small sample size according to Nei $1978 ;{ }^{2}$ Average inbreeding coefficient with correction for small sample sizes; ${ }^{3}$ Average gene diversity within populations; ${ }^{4}$ Average gene diversity between populations; ${ }^{5}$ Coefficient of gene differentiation; ${ }^{6}$ Standard deviations were estimated by Jacknifing over loci (200 replications); ${ }^{7}$ Confidence intervals were obtained through 1000 bootstraps over all loci

Table 5. Summary of the AMOVA within and among yellow root cassava accessions

\begin{tabular}{lcccccccc}
\hline Source & df & SS & MS & Est. Var. & $\%$ & Stat & Value & Probability $^{1}$ \\
\hline Among Pops & 3 & 224.551 & 74.850 & 3.966 & $20 \%$ & & & \\
Within Pops & 60 & 926.184 & 15.436 & 15.436 & $80 \%$ & & & \\
Total & 63 & 1150.734 & & 19.403 & $100 \%$ & PhiPT & 0.204 & 0.010 \\
\hline
\end{tabular}

${ }^{1}$ The probability is based on permutation across the full data set. PhiPT is a statistic measure for comparison between co-dominant data sets 


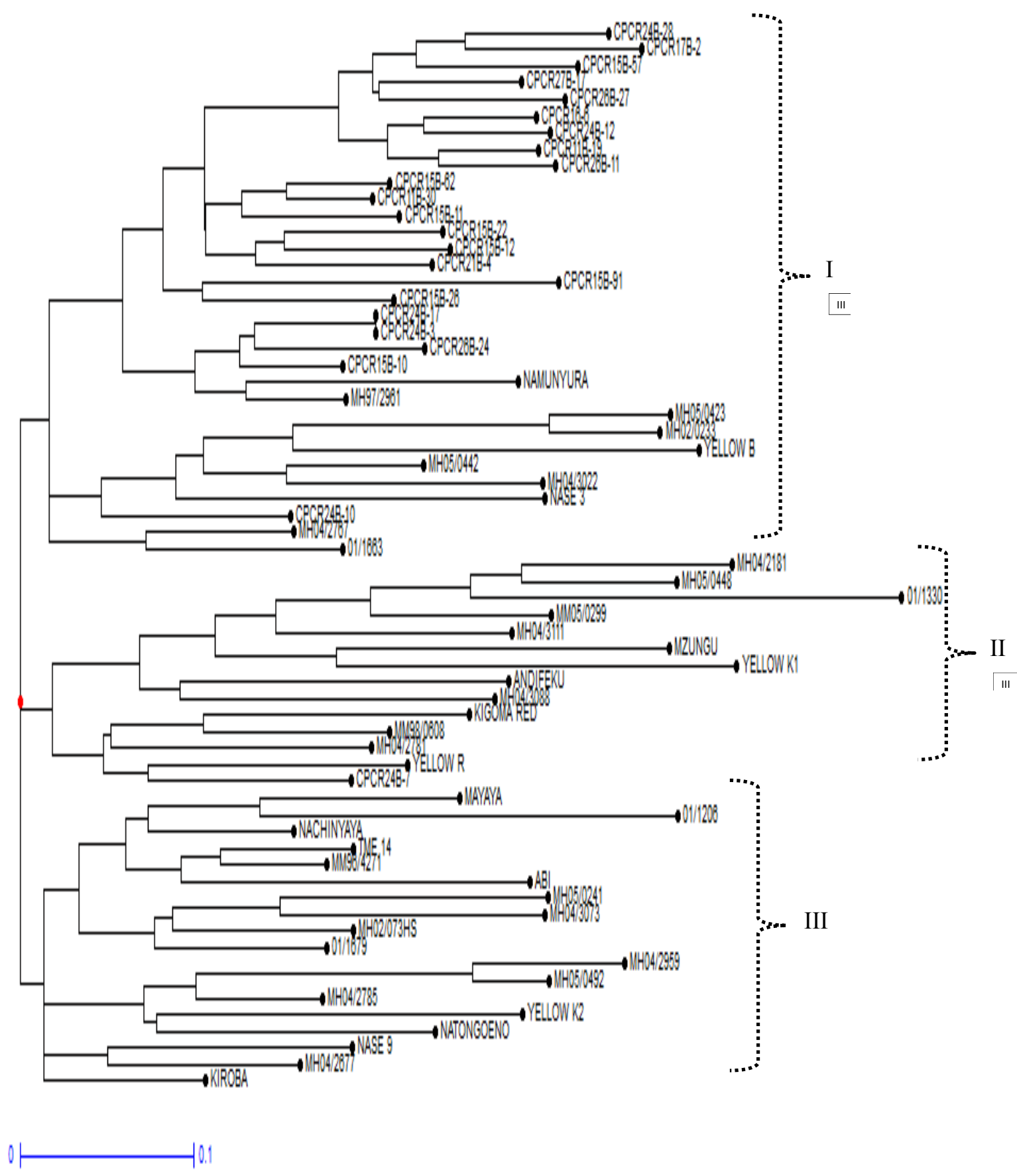

Figure 1. Dendrogram of 64 cassava accessions based on morphological data

Prefix to accessions: CPCR - CIAT accessions; MH/MM/01 - IITA accessions; Others - local names. The white root cassava accessions are Kiroba, Kigoma Red, NASE 9, NASE 3, Mzungu, TME 14, MH97/2961, MM96/4271, and Nachinyaya 


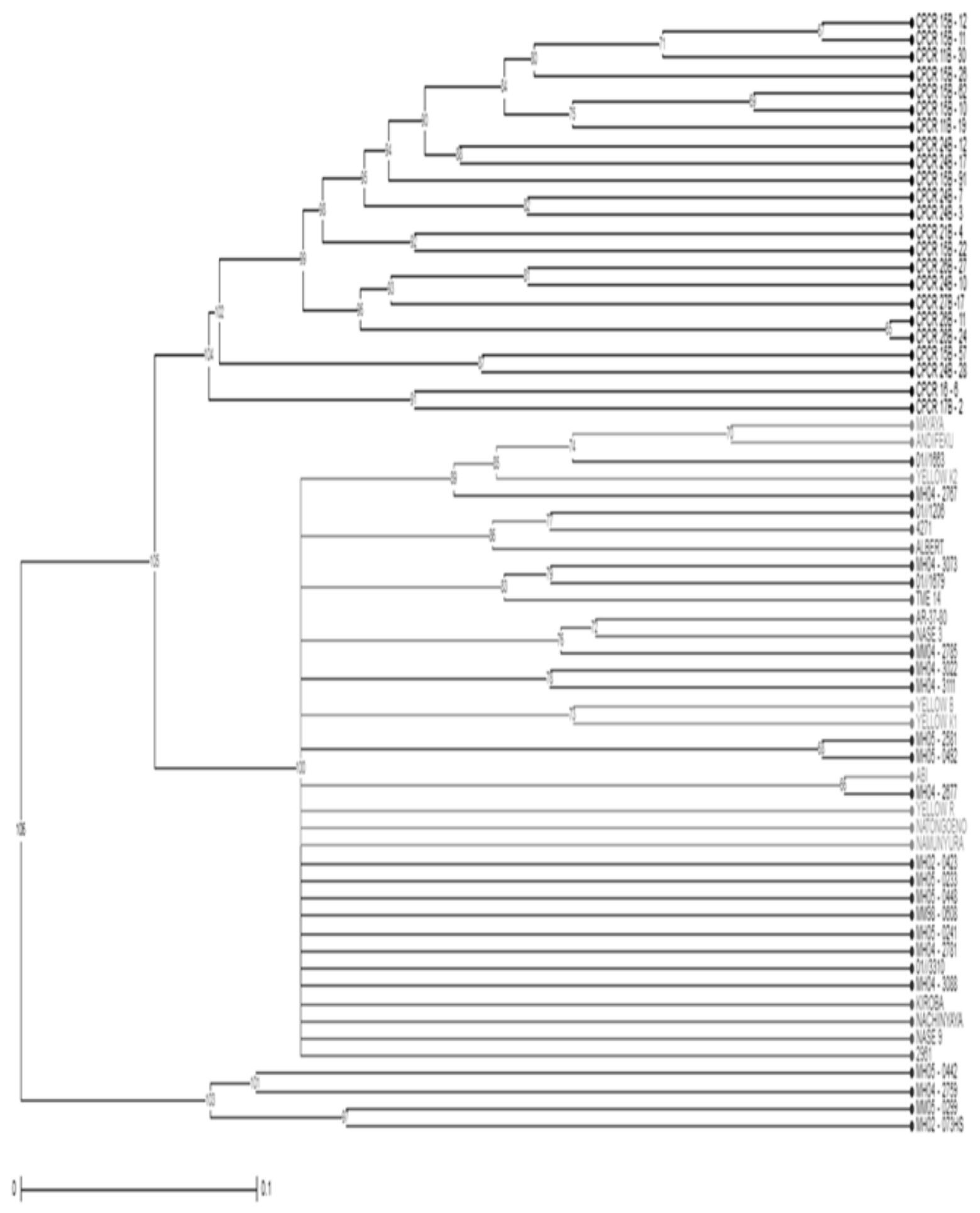

Figure 2. Dendrogram of 64 cassava accessions based on SSR allelic data

The white root cassava accessions are Kiroba, Kigoma Red, NASE 9, NASE 3, Mzungu, TME 14, MH97/2961, MM96/4271, and Nachinyaya 


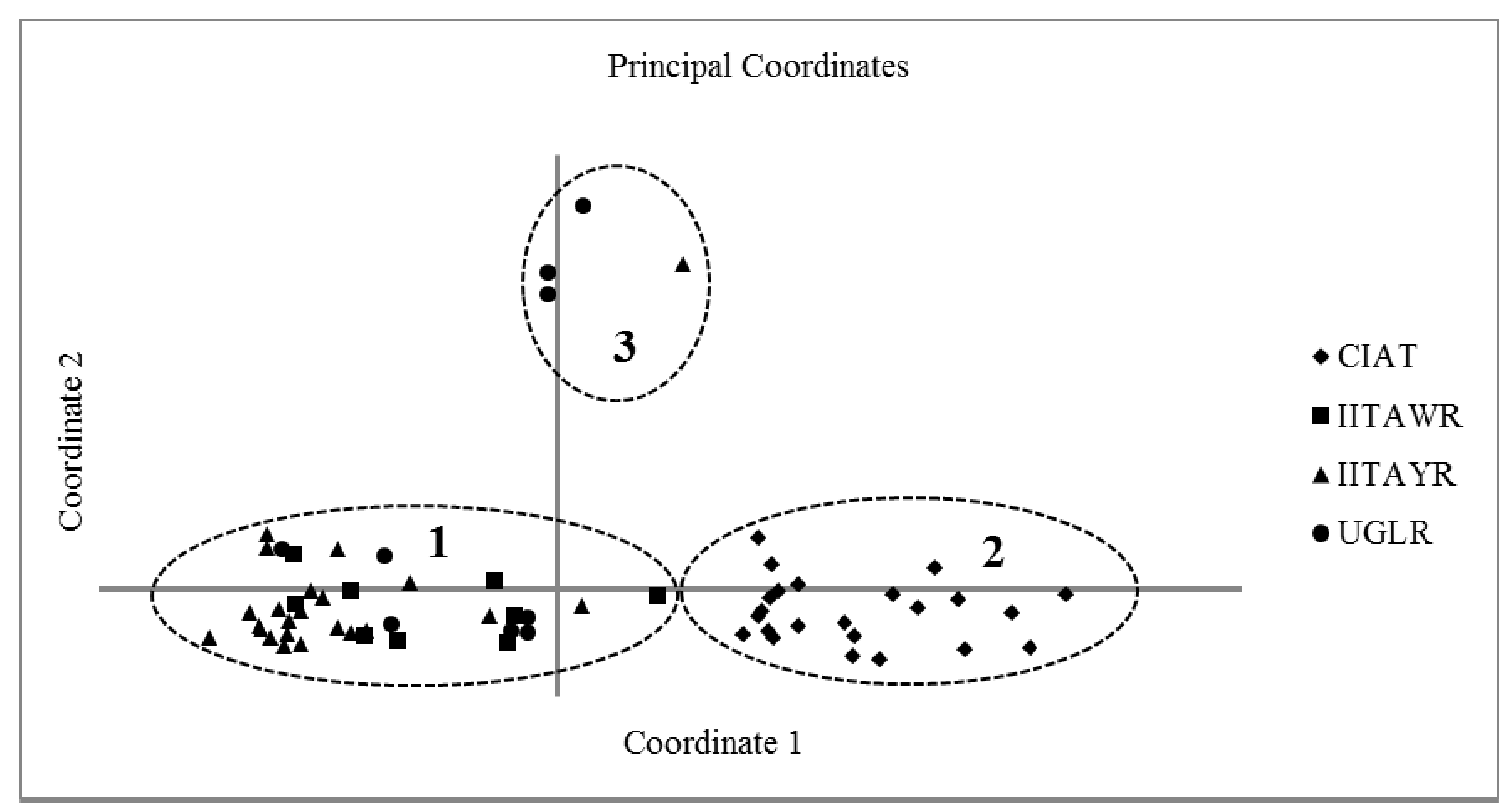

Figure 3. Scatter plot of SSR marker diversity in cassava accessions

CIAT: genotypes from CIAT; IITAYR: yellow root genotypes from IITA; UGLR: Ugandan landraces; IITAWR: white root genotypes from IITA. The plot was constructed using values computed from Jaccard's similarity matrix. Coordinates 1 and 2 explain $33 \%$ and $19 \%$ of the variance observed, respectively. 